American Journal of Pharmaceutical Education 2017; 81 (2) Article 27.

\title{
RESEARCH
}

\section{Best Practices in Establishing and Sustaining Consortia in Pharmacy Education}

\author{
Jennifer Danielson, PharmD, MBA, ${ }^{\mathrm{a}}$ Ana Hincapie, $\mathrm{PhD},{ }^{\mathrm{b}}$ Gina Baugh, PharmD,${ }^{\mathrm{c}}$ Luke Rice, MEd, ${ }^{\mathrm{d}}$ \\ Erin Sy, BS, ${ }^{a}$ Jonathan Penm, PhD, BPharm, ${ }^{b}$ Christian Albano, PhD, MBA, MPH ${ }^{\mathrm{e}}$ \\ ${ }^{\text {a }}$ University of Washington, Seattle, Washington \\ ${ }^{\mathrm{b}}$ University of Cincinnati, Cincinnati, Ohio \\ ${ }^{\text {c }}$ West Virginia University, Morgantown, West Virginia \\ ${ }^{\mathrm{d}}$ Washington State University, Pullman, Washington \\ ${ }^{\mathrm{e}}$ Concordia University Wisconsin, Mequon, Wisconsin
}

Submitted September 25, 2015; accepted April 5, 2016; published March 25, 2017.

Objective. To describe best practices, necessary resources, and success or lessons learned from established consortia in pharmacy education.

Methods. Using semi-structured interviews and qualitative analysis, interviews with members of established consortia in pharmacy education were conducted until saturation was reached. Themes were analyzed and meaningful descriptions of consortia characteristics were developed using systematic text condensation.

Results. Thirteen interviews were conducted. The primary purpose for forming a consortium was identified as threefold: share ideas/best practices; facilitate collaboration; and perform shared problemsolving. For experiential education consortia, two additional purposes were found: share capacity for practice sites, and promote standardization across programs. When investigating best practices for established consortia, three main themes were identified. These included strategies for: (1) relationship building within consortia, (2) successful outcomes of consortia, and (3) sustainability. Successful outcomes included scholarship and, sometimes, program standardization. Sustainability was linked to structure/support and momentum. Respect was considered the foundation for collaborative relationships to flourish in these consortia.

Conclusions. Pharmacy education consortia form through a process that involves relationship building to produce outcomes that promote sustainability, which benefits both pharmacy schools and individual faculty members. Consortium formation is a viable, productive, and often necessary institutional goal for pharmacy schools.

Keywords: pharmacy education, qualitative research, consortium, experiential learning, educational assessment

\section{INTRODUCTION}

Many members of the American Association of Colleges of Pharmacy have discovered the advantages of working together across schools to achieve common goals. Some individuals have formed education consortia (associations of individuals from multiple schools for the purpose of participating in common activities or achieving common goals) and discovered how membership in a consortium related to their area of expertise benefits

Corresponding Author: Jennifer Danielson, University of Washington School of Pharmacy, Box 357630, Office of Professional Pharmacy Education, South Campus Center, Suite 244, 1601 NE Columbia Road, Seattle, WA 98195. Tel: 206-543-1924. Fax: 206-221-2689. E-mail: jendan@uw.edu their potential for collaboration. Examples of successful consortia in higher education include the Committee on Institutional Cooperation, which includes 15 member schools from the Big Ten conference (established 1958), and the Five College Consortium comprised of four liberal arts colleges in the Northeast (established 1965). Many practice-related consortia also exist for clinical practice reasons, such as to publish consensus statements and to establish practice standards. Consortia specific to pharmacy education provide a forum for members to learn from each other and facilitate shared programs, curricula, and projects that produce scholarship in the advancement of pharmacy education practices. These consortia have grown in numbers and in visibility for their accomplishments in recent years. ${ }^{1-9}$ As such, members of 


\section{American Journal of Pharmaceutical Education 2017; 81 (2) Article 27.}

the academy would benefit from a greater understanding of the necessary steps to establish a successful consortium, a list of necessary resources, and information about what it takes to sustain one.

Only two publications have attempted to explain how and why pharmacy consortia exist. Duke and colleagues outlined the development of a pharmacy education consortium in the Southeast, ${ }^{2}$ and Rice proposed a model for how another similar consortium formed in the Northwest. ${ }^{10}$ Both of these successful pharmacy education consortia focus on experiential education. Defining best practices and lessons learned from additional consortia already in existence, especially those considered to be successful leaders in their fields, would inform others and provide guidance for new or struggling consortia. In 2013, a task force was appointed by the Chair of the Council of Faculties to summarize the best practices from established consortia within the academy. This article presents the results of this project.

\section{METHODS}

Qualitative analysis of semistructured interviews with key individuals of established consortia in pharmacy education was used to identify best practices. Modeled after work of Warholak and colleagues ${ }^{11}$ and Sturpe, ${ }^{12}$ a qualitative approach using interviews was chosen because such methods facilitate insight about developmental processes and can be used to understand complex and contextual characteristics. ${ }^{13}$ Meaningful descriptions of the configuration and distinguishing characteristics of consortia were developed during analysis through systematic text condensation ${ }^{14}$ in order to identify why and how consortia exist and what makes them successful. This project was approved as exempt by the University of Washington Human Subjects Review Board.

Purposeful sampling was used to identify key individuals for interview. ${ }^{15}$ Interviews were conducted between October 2014 and March 2015. Key individuals were chosen for their membership in known consortia, especially those considered leading, successful organizations. First, individuals were identified through a literature search (conducted in December 2014) for authors of publications regarding consortia related to pharmacy education that were cited in PubMed. Second, additional individuals were identified through a hand search of the American Journal of Pharmaceutical Education and the American Association of Colleges of Pharmacy Annual Meeting abstracts pertaining to consortia in pharmacy education for years 2005-2014. Third, results from a survey conducted by Baugh and colleagues in 2012, ${ }^{16}$ which contained the first comprehensive list of pharmacy experiential education consortia, yielded additional individuals to interview. The number of interviews was to be capped at the point when saturation was achieved (ie, responses cease to reveal new information and consistent themes begin to emerge). ${ }^{17-18}$

The semistructured interview guide was developed according to published guidance on conducting effective interviewing ${ }^{19}$ and based on previous work by Rice, ${ }^{10}$ which reported factors that define success in pharmacy experiential education consortia and proposed a model for sustaining consortia. The guide was pilot tested with two consortium members and edited by investigators prior to further use and data collection. Interviewers used the guide to make sure all desired issues were explored but did not always use exact wording or the predetermined order of the questions. Respondents were encouraged to elaborate and share stories of their experience for which direct quotes were written down whenever possible. Detailed interview notes on key issues identified by participants were taken and then rewritten for clarity. Notes were de-identified prior to further analysis.

In total, four investigators conducted the interviews and iteratively discussed themes they identified with the entire research team to triangulate the data. Iterative written summaries were developed with the team via shared Web documents. Responses were repeatedly grouped by type of consortia, question categories, and emerging themes. Then, two of the investigators repeatedly reviewed all interview notes and shared documents, compared coded responses, wrote summaries, and discussed results. This iterative process of coding, writing, discussion, and rewriting summaries of the themes helped investigators to interpret and refine the results. ${ }^{14}$ Before submission for publication, written results were shared with the interviewees to verify the trustworthiness of the data.

\section{RESULTS}

Thirteen interviews had been conducted when saturation was reached. ${ }^{20}$ Demographics for the participants are shown in Table 1. These results represent a wide number of pharmacy education consortia with responses from 12 of the $16(75 \%)$ consortia known to exist at the time of this study (four of the 10 experiential education consortia in the US, ${ }^{16}$ the only experiential education consortium in Canada, and at least one member of every known assessment and research and education consortia).

The primary purpose for forming a consortium was identified as threefold: share ideas/best practices; facilitate collaboration; and perform shared problem-solving. One of the participants summarized the purpose of a consortium as providing a forum for speaking to other individuals confidentially and working through similar 


\section{American Journal of Pharmaceutical Education 2017; 81 (2) Article 27.}

Table 1. Demographics of Interview Participants, $\mathrm{N}=13$

\begin{tabular}{llc}
\hline Consortium Type & \multicolumn{1}{c}{ Position } & No. \\
\hline Experiential Education & Faculty Directors of EE & 5 \\
(EE) & & \\
& Professional Staff & 1 \\
Research and Education & Deans/CEOs & 3 \\
& Faculty Member & 1 \\
Assessment & Faculty Directors of & 3 \\
& Assessment & \\
\hline
\end{tabular}

challenges. The assumption was that if a problem is occurring in one place, it is probably occurring elsewhere. And, such problems could be solved through working together within a consortium.

For experiential education consortia, two additional purposes were found: share capacity for practice sites, and promote standardization across programs. Participants explained that experiential education consortia formed among schools in geographical regions where competition for practice sites in which to place students was fierce. Many of these consortia formed during implementation of the entry-level PharmD degree or ACPE Standards 2007, both of which significantly increased the requirements for experiential education in pharmacy school curricula. At the same time, the number of schools and enrollments in pharmacy education grew substantially. Consequently, forming an experiential education consortium among schools with overlapping geographical regions promoted: collective problem-solving on mutual challenges; sharing of limited capacity for student placements; and collaboration over competition, which helped schools meet new demands by streamlining requirements for their preceptors.

When investigating best practices for established consortia, three main themes were identified for producing a successful consortium: relationship-building; successful outcomes; and sustainability (Figure 1). A summary of the best practices identified from these themes is presented in Table 2 .

\section{Relationship Building}

All participants recognized the value in belonging to a consortium because they believed it provided opportunities to meet and build relationships with other people in their field, allowing them to share ideas and best practices. Once relationships within a consortium were established, the purpose usually evolved for individual members as the consortium became a support group. Participants repeatedly reported that the personal and professional reward from relationships they built within consortia was a career highlight. Participants frequently stated they could

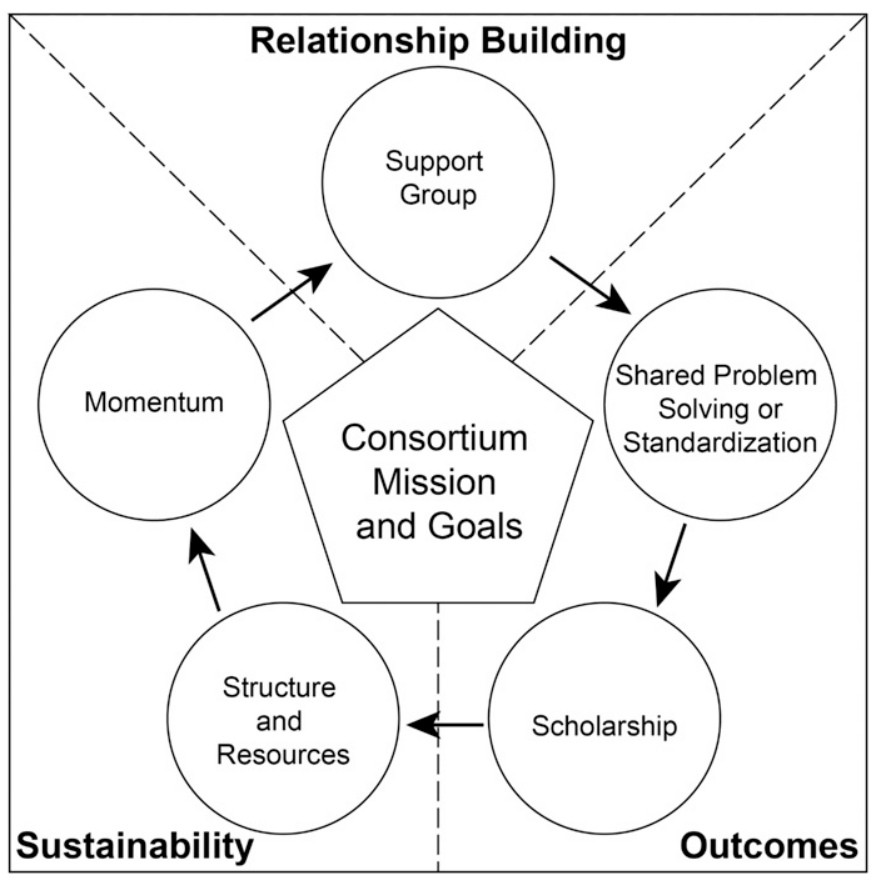

Figure 1. Model for a Successful Consortium.

call on each other for advice, because they felt their consortium members were helpful, open, and sharing. In effect, consortium membership reinforced the value of each person within it.

Enhancing the quality of relationships built within a consortium was seen as particularly important for success. A progression and mutual reinforcement between quality of relationships and consortium accomplishments became apparent. Attention to improving the quality of relationships seemed to help members progress toward their consortium goals. When members liked each other, they made getting together and going to consortium meetings a priority. As members got along better, they were motivated to work together and thus became more likely to accomplish their goals. One participant referred to this concept as "chemistry" within his consortium. He felt that as they nurtured this "chemistry" within the group, they became more productive and less likely to dissolve. For this reason, some participants said they intentionally planned social time as part of their meetings so that relationships grew personally as well as professionally. Although participants from experiential education consortia did not intentionally include socialization in their meetings, they claimed to "bond" through common understanding of job demands.

Consortia also provided a forum for individuals to talk to others who are facing similar challenges. In this regard, consortia were especially beneficial to individuals unable to discuss issues with others within their own 


\section{American Journal of Pharmaceutical Education 2017; 81 (2) Article 27.}

Table 2. Best Practices for Pharmacy Education Consortia

\begin{tabular}{|c|c|}
\hline Theme/subtheme & Best practices \\
\hline $\begin{array}{l}\text { 1. Relationship Building } \\
\text { Support Group }\end{array}$ & $\begin{array}{l}\text { 1. Find ways to foster collegiality and build respect among all members. When members bond, } \\
\text { they develop valued friendships and appreciate learning from the diversity of intellect. } \\
\text { 2. Establish regular meetings, ideally monthly and at least one face-to-face meeting a year. } \\
\text { 3. Having a loose structure for the consortium may enhance relationship building. } \\
\text { 4. Onsite visits by consortium members to each other's institutions can establish rapport and } \\
\text { respect. } \\
\text { 5. Form subgroups within large consortia ( } 10 \text { or more schools) to foster relationship building. } \\
\text { 6. Repair strained relationships. If general agreement is not possible, find common ground in } \\
\text { smaller projects or establish a few subgroups to give the consortium members purpose and } \\
\text { common focus. } \\
\text { 7. Consortium membership should be embraced. Deans are encouraged to mandate participation } \\
\text { in consortia, because membership improves relationships and collaboration between competitor } \\
\text { schools. }\end{array}$ \\
\hline
\end{tabular}

2. Successful Outcomes Standardization

Scholarship

3. Sustainability Structure and Support

Momentum
1. Standardization across schools should be seen as a positive result of shared problem solving.

2. Standardizing schedules and evaluation tools for experiential education consortia members make it easier for preceptors to host and evaluate students across multiple schools.

1. Leadership is an important factor in producing scholarship.

2. Include scholarship in the consortium strategic plan and mission.

3. Identify an idea that is practical and favorable for everyone. Do not produce scholarship just for the sake of it.

4. Dedicating one member to scholarship efforts will ensure work is disseminated if the consortium experiences turnover.

5. Members of established consortia should seek to collaborate with other consortia, not just within individuals of their own consortium.

1. Create bylaws for the consortium.

2. Emphasize the value of membership and prioritizing goals of the consortium.

3. Establish a strategic plan for the consortium.

4. Establish regular meetings, ideally monthly and one face-to-face meeting a year.

5. Form subgroups within large consortia (10 or more schools) to maintain clear goals for each member.

6. Obtain dean support for ongoing involvement with the consortium.

1. Leadership is an important component in maintaining momentum. Leaders should set the direction and motivate the group toward the goal.

2. Regular progress reports facilitate accountability and momentum for consortia.

3. Report regularly to respective deans about progress on projects and discussions held at consortium meetings.

4. Consider making participation in projects a requirement of membership in the consortium.

5. Regularly highlight, share and celebrate best practices and novel ideas revealed through consortium collaborations. school or organization (either because there were no others with similar jobs or all others were subordinates). Some participants said they felt like "islands" within their own schools, but within the consortium they received support as they shared ideas or concerns.

However, it was also noted that competition within a consortium could affect relationships. As one experiential education consortium participant said, "We are a group of schools with common interests but also competitors for students, sites, and preceptors." Another participant explained that differing opinions and strong positions could pull a consortium apart. Hence, repairing strained relationships and focusing on common goals were considered important.

As membership in consortia grew in size, dynamics of relationships were often stressed as everyone was expected to contribute. Consequently, participants believed that forming subgroups was particularly useful when 


\section{American Journal of Pharmaceutical Education 2017; 81 (2) Article 27.}

consortiums became too large (10 or more schools). Subgroups allowed members to work together to complete projects or accomplish specific objectives. Subgroups provided a sense of purpose and accountability among a manageable number of individuals with common interests. Ultimately, subgroups promoted relationship building through communication and cooperation toward a mutual goal.

\section{Successful Outcomes}

Two subthemes emerged as outcomes of successful consortia: standardization and scholarship. Standardization. Standardization was an explicit goal in all experiential education consortia included in this study. Because experiential education consortia often shared sites and preceptors, standardizing schedules and evaluation tools made it easier for preceptors to host and evaluate students across multiple schools. As such, member schools reported having standardized placement schedules, common evaluation tools, common calendars for rotation blocks, and joint preceptor development offerings or requirements. Multiple participants reported that their consortium aimed to streamline administrative issues as much as possible because of the number of shared sites. This process was expressed by one participant, "We are a group of multiple people doing similar things, so it makes sense to standardize things across what we do."

Although standardization was an explicit outcome in all experiential education consortia, this was not the case in other types of consortia. Some participants noted that similarities in programs occasionally occurred as a result of discussions within the consortium, but they did not prefer to use that terminology. They did not refer to it as "standardization," but preferred to call it "shared problemsolving" or "shared solutions" instead. Another participant said, "If it happens that we end up adopting similar things, it's probably because we all talked. But it's not a specific aim." This participant explained that their consortium members are careful not to have an explicit agenda that would set policy or take a public stance.

Scholarship. For the purpose of this project, scholarship was defined as disseminating results to others either through publication or presentation. Scholarship outcomes included posters, presentations, journal articles, and other publications. All participants recognized that collaborations within consortia were likely grounds for producing scholarship. As such, the need for scholarship was written into the bylaws of some consortia. Some placed additional emphasis on scholarship by ensuring all projects were designed to be measured and disseminated. Building scholarship into the consortium provided additional benefit to experiential education consortia participants
Opportunities to present platform presentations and posters together allowed consortia participants to travel to annual meetings, as travel was not otherwise funded. Leadership was considered helpful in driving the conversation toward scholarship. For example, one participant stated a leader was needed "to force the ideas to come out, then the group dynamics allowed ideas to float to the top."

Scholarship, however, was not always a clear outcome for all consortia. An experiential education consortium participant pointed out that scholarship participation depended on the individuals and schools involved and whether participants were staff or faculty members. For some participants, scholarship may not be an expectation or priority in their jobs. Some participants also highlighted that scholarship was an indirect outcome of the consortium's overarching aim, which was to advance methods in pharmacy education in general. Thus, many participants have developed white papers rather than research articles. One participant illustrated this concept when he claimed that consortia are unintentional facilitators and incubators of scholarship.

\section{Sustainability}

All participants stated that their consortium was sustainable. This theme of sustainability was attributed to communication, structure/support, and momentum. Contributors to momentum included leadership and commitment within a consortium.

Structure and Resources. In this subtheme, regular meetings were mentioned as an important structure for creating sustainability. In fact, all participants reported meeting face-to-face at least once a year, except participants from an international consortium where face-toface meetings were not possible. Frequent communication seemed to be key to maintaining momentum. Although the primary purpose of regular meetings was to ensure sustainability, it also had a secondary effect that strengthened relationships between members. This was further emphasized when the meetings were face to face. One participant said, "I'd like us to collaborate more, face to face. When we have retreats together, that really jumpstarts us. Teleconference meetings can only go so far in keeping each other updated and accountable and cannot substitute for the power of human interaction." Another participant summarized how valuable it was for all consortium members to be in one place at one time when he said, "It's the most important thing I put on my calendar."

Face-to-face meetings can be expensive and timeconsuming, however, so consortia also used teleconferences to accomplish an ideal meeting frequency. These teleconference meetings were considered important for 


\section{American Journal of Pharmaceutical Education 2017; 81 (2) Article 27.}

maintaining accountability. For example, one participant attributed their sustainability to monthly conference calls, since it is a time when all project leads must report to each other. An experiential education consortium participant expressed that the consortium members need "connectivity" to avoid getting too busy with daily responsibilities and forgetting to collaborate.

Numerous participants explicitly indicated that having their dean's support allowed their consortium to remain sustainable. Participants universally agreed that having support from their administration in the form of resources (financial or protected time) made it possible to attend meetings and devote time to projects related to the consortium. Participants that explicitly indicated having support from the dean consistently perceived their consortium as sustainable.

While support for individuals to participate in consortia from their own administration was important for sustainability, the importance of sharing financial resources within or across members of a consortium was variable. The most successful report of shared resources came from one consortium that pooled funds to hire a joint project manager. While sharing financial resources was found to be beneficial, it did not appear to be an essential structure for a sustainable consortium. Other ways that costs were shared across members included rotating the site for annual meetings and splitting costs for meetings across all member schools.

Momentum. Leadership was an important component in maintaining momentum. Leaders were described as setting a clear direction for the team and motivating the group toward a goal. As one participant said, "The chair is responsible for encouraging members to meet their deadlines." Another participant emphasized that without a strong leader a consortium can lose an entire year of productivity.

Only some of the consortia represented were formally structured (ie, held elections). Many consortia were informally organized and structured around group consensus and flexible agendas. In one case, everyone submitted agenda items and the group discussed problems until they were resolved. These "loose" agendas were considered ideal by some participants as it allowed more time for conversation. One participant likened their leadership to that of a pirate ship, "Someone speaks the loudest, so we follow them until they are done. We tend to let the leader lead us to the treasure." While this group relied on the individual who was the most vocal, the consortium allowed everyone to take turns talking in order to reach agreement. Participants also agreed that rotating leadership would keep a consortium sustainable while maintaining flexibility.
Informal structures were also recognized as a threat to momentum. As one participant said, "One of the beauties of the consortium is that it is an informal organization. But, this also works against [us] at times, because [we] do not feel the pressure to do things." This consortium met quarterly to maintain accountability yet still struggled to progress quickly on projects.

Other underlying components of momentum were the commitment, dedication, and contributions that each individual made to their consortium. Multiple participants described that it was important for all members to understand that their participation was necessary. Accountability and commitment to the consortium seemed to be understood as part of being in a consortium. Even when momentum slowed, commitment helped members overcome obstacles. Another participant explained that sustainability "takes work of the individuals involved to make things happen. . .it's based on willpower of individuals." This participant, however, cautioned that sustainability built exclusively on individuals can stall when turnover in positions occurs.

\section{DISCUSSION}

Overall, these results confirm Rice's model for successful experiential education consortia ${ }^{10}$ and demonstrate that it applies to all pharmacy education consortia, with the exception of one construct (ie, standardization). For experiential education consortia, standardization is an intentional aim, whereas it is an unintentional product for others. Thus, the concept of "shared problemsolving" may simply be an informal way of referring to a similar goal. Consequently, this modification of Rice's model for consortium development provides insight on how a consortium forms and succeeds (Figure 1), which is important for existing consortia on how to improve sustainability.

The single greatest benefit of belonging to a consortium was found to be collaborative relationships (both personal and professional) between individual members. Having a support group of individuals that know and appreciate the unique demands of one's position establishes a sense of belonging that fosters mutual respect and trust. Participants expressed that this type of support is personally rewarding and contributes to their professional development. As such, it may be suggested that an important side effect of consortium membership may be improved job performance and satisfaction as well as reduced burnout/turnover. This form of professional development could contribute to greater stability for pharmacy education in a region served by a consortium.

Based on themes identified in this study, the investigators developed a theory for how collaborative 


\section{American Journal of Pharmaceutical Education 2017; 81 (2) Article 27.}

relationships are built within successful pharmacy education consortia (Figure 2). This theory shows that participants build relationships within their consortium through communication (meetings) and cooperation (shared missions and challenges). Regarding communication, the frequency and method were considered important for many participants. Although the meeting frequency ranged from weekly to annually, monthly was preferred. Furthermore, face-to-face meetings were considered essential for members to get to know each other well.

To achieve group bonding, however, communication and cooperation must be built upon an important underlying value: respect. As relationships grew through communication and cooperation, the respect between consortium members was reinforced further. This concept was especially evident in experiential education consortia. One individual called it "chemistry," while another participant called it "flow." Regardless of terminology, pharmacy education consortia members build successful relationships when individuals who respect each other use timely, face-to-face communication as they cooperate collegially on shared goals.

In addition to benefits for individual members, these results suggest that schools may benefit from consortia in the form of reduced competition and improved efficiency. Forming a consortium may create a critical mass of individuals within a field large enough to produce innovation where not possible alone. The collective knowledge and learning that a consortium provides may allow members, and their respective schools, to engage in shared problem-solving and best practices, all of which may improve efficiency. Consortia have the potential to help member schools avoid common pitfalls and amplify successes. Such collaboration may also help schools meet

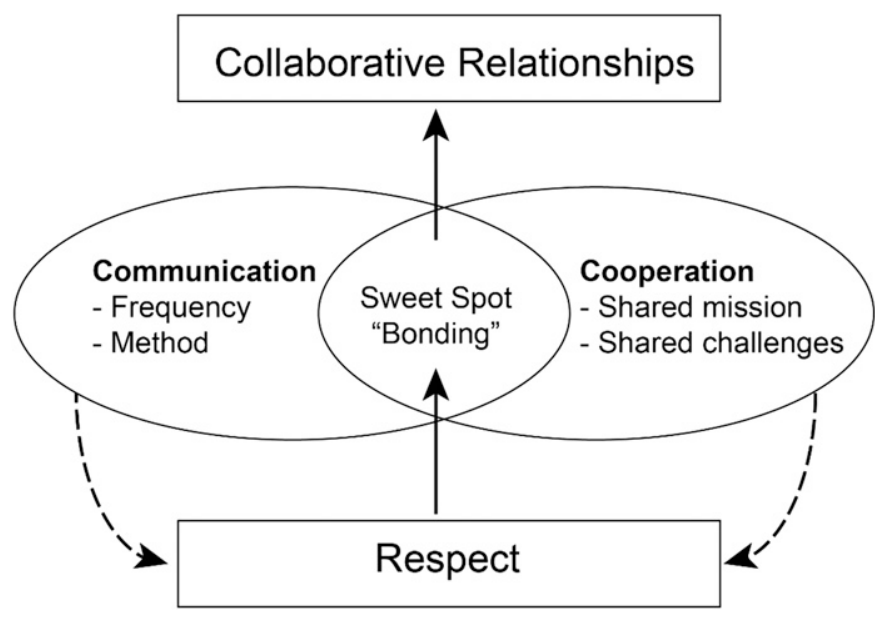

Figure 2. Diagram of Relationship Building Within Consortia. new accreditation standards and future demands in pharmacy education.

A rotating champion who would be responsible for motivating members and holding others accountable seemed to be the recommended leadership approach for pharmacy education consortia. As such, consortium leadership can be considered professional development for individual faculty and staff members and a rich training ground for future leaders in pharmacy education. Experienced faculty members belonging to consortia should be careful to provide mentoring and guidance to their rotating champions. School administrators should celebrate leadership opportunities for their faculty and staff members within consortia and recognize this growth as part of the professional advancement process.

We found mixed perceptions about the value of scholarship within and resulting from consortia membership. Despite key individuals being selected from published works, many participants actively denied that scholarship was a stated or explicit goal of their consortia. Few mentioned scholarship spontaneously as a benefit of belonging to a consortium and most only addressed it when asked directly. From this, one can infer that while individuals use their work with consortia to benefit professionally, scholarship is not necessarily considered an intentional aim of consortia as a whole. In addition, most participants were faculty members with large administrative workloads and some were professional staff members. If one presumes that these individuals do not have positions where scholarship is a priority, these results may support the conclusion that scholarship is not a high priority for most consortia in pharmacy education.

After the initial burst of activity that often happens when a consortium forms, a secondary lull can threaten the existence of a consortium. Several mechanisms for improving sustainability were discussed in this report. In addition to those recommendations, consortia members should be mindful to continually highlight, share and celebrate best practices and novel ideas revealed through collaborations. Continual searching for galvanizing initiatives will keep a consortium alive and drive innovation. Capitalizing upon innovations developed from consortium work can propel individuals who participate, benefit schools involved, and improve the quality of pharmacy education in general.

Although efforts were made to identify and include representatives from all known consortia in pharmacy education, we cannot guarantee that all existing consortia are represented in these results. Nevertheless, saturation was achieved after 13 interviews and increasing the number of participants may not have yielded new themes. Additionally, we attempted to capture experiences of 


\section{American Journal of Pharmaceutical Education 2017; 81 (2) Article 27.}

subjects with a wide range of consortia membership and engagement histories to limit the potential for selection bias.

\section{CONCLUSION}

Consortia formation is a viable, productive, and (at times) necessary institutional goal for pharmacy schools and programs. Consortium membership facilitates relationships among faculty and staff members, which promotes professional development, drives innovation, and fosters collaboration across institutions to improve efficiency.

\section{ACKNOWLEDGMENTS}

We would like to acknowledge contribution to this work from Deborah Sturpe, Clinical Associate Professor at University of New England College of Pharmacy, for her consultation on interviewing techniques and qualitative analysis methods. We would also like to acknowledge Charles Peterson, Dean of North Dakota State University, for his consultation, which helped improve our understanding of the role of consortia.

\section{REFERENCES}

1. Mort JR, Odegard PS, Cochran GA. Geriatric education centers: Teaching and learning opportunities for pharmacists. Am J Pharm Educ. 2005;69(2):Article 31.

2. Duke LJ, Unterwagner WL, Byrd DC. Establishment of a multistate experiential pharmacy program consortium. Am J Pharm Educ. 2008;72(3):Article 62.

3. Brackett PD, Byrd DC, Duke LJ, et al. Barriers to expanding advanced pharmacy practice experience site availability in an experiential education consortium. Am J Pharm Educ. 2009;73(5):Article 82. 4. Kehrer JP, Schindel TJ, Mann HJ. Cooperation in pharmacy education in Canada and the United States. Am J Pharm Educ. 2010;74(8):Article 142.

5. Huston SA, Zdanowicz MM, Fetterman JW. Pharmacogenomics in advanced pharmacy practice experiences. Curr Pharm Teach Learn. 2010;2(4):196-203.
6. McDuffie CH, Duke LJ, Stevenson TL, et al. Consortium-based approach to an online preceptor development program. Am J Pharm Educ. 2011;75(7):Article 135.

7. Danielson J, Ramirez J, Krueger J et al. The capacity ratio as a measure of solvency in experiential education. Am J Pharm Educ. 2011;75(10):Article 198.

8. Duke LJ, Staton AG, McCullough ES, et al. Impact of advanced pharmacy practice experience placement changes in colleges and schools of pharmacy. Am J Pharm Educ. 2012;76(3):Article 49. 9. Janke KK, Seaba HH, Welage LS, et al. Building a multiinstitutional community of practice to foster assessment. Am J Pharm Educ. 2012;76(4):Article 58.

10. Rice L. Developing a model of successful collaboration: the Northwest Pharmacy Experiential Consortium [masters thesis]. Cheney, WA: Eastern Washington University; 2011.

11. Warholak TL, Holdford DA, West D, et al. Perspectives on educating pharmacy students about the science of safety. Am J Pharm Educ. 2011;75(7):Article 142.

12. Sturpe DA. Objective structured clinical examinations in Doctor of Pharmacy Programs in the United States. Am J Pharm Educ. 2010;74(8):Article 148.

13. Sofaer S. Qualitative methods: what are they and why use them? Health Serv Res. 1999;34(5 Pt 2):1101-1118.

14. Malterud K. Systematic text condensation: a strategy for qualitative analysis. Scand J Public Health. 2012;40(8):795-805. 15. Teddlie C, Yu F. Mixed methods sampling: a typology with examples. J Mix Methods Res. 2007;1(1):77-100.

16. Baugh G, Ernthausen L, Young E. Experiential education workload and workforce survey. Poster presented at: American Association of Colleges of Pharmacy Annual Meeting; July 16, 2012. Orlando, FL: Abstract 15.

17. Richards L. Handling Qualitative Data: A Practical Guide. London, UK: Sage Publications; 2005.

18. Seidman I. Interviewing as Qualitative Research: A Guide for Researchers in Education and Social Sciences. 4th ed. New York, NY: Teachers College Press; 2013.

19. Merriam S. Conducting effective interviews. In: Qualitative Research: A Guide to Design and Implementation. 2nd ed. San Francisco, CA: Jossey-Bass; 2008:87-115.

20. Guest G, Bunce A, Johnson L. How many interviews are enough? An experiment with data saturation and variability. Field Meth. 2006;18(1):59-82. 